\title{
Effect of selective and non-selective beta blockade on pulmonary function and tracheobronchial mucociliary clearance in healthy subjects
}

\author{
D PAVIA, JRM BATEMAN, AM LENNARD-JONES, JE AGNEW, SW CLARKE \\ From the Departments of Thoracic Medicine and Medical Physics, Royal Free Hospital and School of Medicine, \\ London
}

ABSTRACT A controlled, double blind, crossover study was carried out to ascertain the effect of single doses of selective (100 $\mathrm{mg}$ atenolol) and non-selective $(160 \mathrm{mg}$ propranolol) beta blocker on pulmonary function and tracheobronchial mucociliary clearance. The study group comprised 12 healthy, young subjects. Adequate and comparable blockade was achieved with both drugs, the administration of which resulted in significantly lower pulse rates (at least up to eight hours after administration of the drug) and systolic blood pressures (three hours after drug administration) than were found with placebo. Small (of the order of $5 \%$ ) but nevertheless statistically significant falls in $\mathrm{FEV}_{1}$ and forced vital capacity accompanied the administration of both beta blockers (but not the placebo) and were measurable up to eight hours after administration of the drug. Indices of pulmonary function had returned to normal by the next day. Peak expiratory flow and indices of small airways function remained unaltered after beta blockade. Mean tracheobronchial mucociliary clearance was depressed after administration of both beta blocking drugs, although the reduction was significant $(\mathrm{p}<0.05)$ only when propranolol was compared with placebo.

Tracheobronchial mucociliary clearance is one of the lungs' non-specific host defence clearance mechanisms. It can be altered by physical factors (such as exercise), environmental pollutants, disease, and pharmacological intervention. ${ }^{1}$ Its control is not well understood. Circulating catecholamines may, however, have a role in the control of mucus transport since the $\beta_{2}$ adrenergic drug terbutaline given either subcutaneously ${ }^{2}$ or orally ${ }^{3}$ to healthy subjects has been reported to result in an increased clearance, though this has been disputed. ${ }^{4}$ Orciprenaline when given to healthy subjects showed a regional effect on tracheobronchial mucociliary clearance. ${ }^{6}$ Adrenaline, isoprenaline, and fenoterol ${ }^{78}$ given topically (by aerosol) have given rise to enhanced tracheobronchial mucociliary clearance in healthy subjects. In patients with chronic bronchitis and asthma $\beta$ agonists tend to enhance clearance. ${ }^{9}$

Address for reprint requests: Dr Demetri Pavia, Department of Thoracic Medicine, The Royal Free Hospital, Pond Street, Hampstead, London NW3 2QG.

Accepted 19 October 1985
The effect of beta blockers on tracheobronchial mucociliary clearance in man is not well documented. It is well known, however, that beta blockers may precipitate asthma in susceptible subjects. ${ }^{10}$ To our knowledge the effect of beta blocking agents on tracheobronchial mucociliary clearance in health has not hitherto been studied. We report a study on the effect of non-selective and selective beta blockade on pulmonary function indices and tracheobronchial mucociliary clearance in 12 healthy subjects.

Mean (SD) physical characteristics and pulmonary function indices for 12 healthy subjects

\begin{tabular}{|c|c|}
\hline 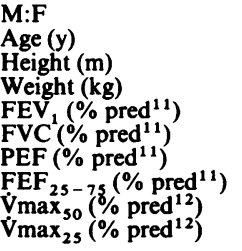 & $\begin{array}{l}6: 6 \\
25(6) \\
1.70(0.03) \\
68(13) \\
125(16) \\
117(15) \\
101(9) \\
113(22) \\
106(21) \\
115(32)\end{array}$ \\
\hline
\end{tabular}

FVC-forced vital capacity; PEF-peak expiratory flow; $\mathrm{FEF}_{25}-75-$ maximum mid expiratory flow; $\max _{50}$, V $\max _{25}$ - flow rates at $50 \%$ and $25 \%$ of vital capacity; \% pred-percentage of predicted value. 
Methods

\section{SUBJECTS}

Twelve healthy volunteers took part in the study. Their physical characteristics and pulmonary function indices (means and standard deviations) are shown in the table. Six subjects (four female) were non-smokers and the remaining six subjects (two female) were current cigarette smokers with a mean (SD) tobacco consumption of 5.1 (8.4) pack years (one pack year $=20$ cigarettes a day for one year). The subjects were selected for the study provided that they had normal pulmonary function and satisfactorily completed a medical questionnaire directed towards past symptoms of chest disorder. Informed written consent was obtained from all the subjects.

\section{STUDY DESIGN}

A controlled, double blind, crossover study (using the double placebo technique) was carried out. The subjects were studied on three occasions at intervals of one week. At each of the three assessments, which followed a 10 minute rest period, the subjects' pulse rate, blood pressure, and pulmonary function were measured. The subjects were then given, in a randomised manner, two tablets to take with a cup of water; the three treatments were $(a)$ one placebo tablet and another containing $160 \mathrm{mg}$ of propranolol, $(b)$ one placebo tablet and another containing $100 \mathrm{mg}$ of atenolol, and $(c)$ two placebo tablets. The subjects (who were all employees of this hospital) were then allowed to proceed with their normal duties. Two hours after the medication their pulse rate, blood pressure, and pulmonary function were once again measured and immediately afterwards they inhaled the test radioaerosol for assessing tracheobronchial mucociliary clearance. Pulse rate and blood pressure were measured again one, three, six, and 24 hours after inhalation of the radioaerosol. Pulmonary function was assessed six and 24 hours after inhalation of radioaerosol, thus ensuring that the forced expiratory manoeuvres did not alter tracheobronchial clearance in the initial six hour period.

PULMONARY FUNCTION, PULSE RATE, AND BLOOD PRESSURE MEASUREMENTS

A Vitalograph spirometer was used to measure $\mathrm{FEV}_{1}$, forced vital capacity (FVC), and maximum mid expiratory flow $\left(\mathrm{FEF}_{25-75}\right)$. Peak expiratory flow (PEF) was measured with a Wright peak flow meter. The flow rates at $50 \%$ and $25 \% \quad\left(\dot{V}_{\max } 50\right.$ and V $\max _{25}$ ) of vital capacity (that is, remaining to be exhaled) were determined from maximal expiratory flow-volume (air) curves obtained with an Ohio 840 piston-cylinder type spirometer connected to a Bryans X-Y recorder. For all pulmonary function indices the highest reading out of three technically. acceptable attempts was recorded.

Measurements of pulse rate and blood pressurß were carried out by the same observer (AM L-J) afteif the subject had rested for 10 minutes; they alway preceded any pulmonary function tests.

\section{TRACHEOBRONCHIAL MUCOCILIARY}

CEEARANCE

For measurement of tracheobronchial mucociliary clearance $^{13}$ polystyrene particles were labelled ${ }^{14}$ witbo technetium $99 \mathrm{~m}$ and inhaled in eight breaths, each of 0.451 , from functional residual capacity (FRC) with three second breath hold. Mean inspiratory flow was recorded by a UV recorder from a pneumotachy graph. An initial deposition count of lung radios activity was taken immediately after inhalation by twin, horizontally opposed anterior-posterior scintip lation counters, ${ }^{15}$ with wide angle lead collimators, further counts were made hourly for six hours with final count at 24 hours. The 24 hour retention was taken to represent "alveolar deposition", that is

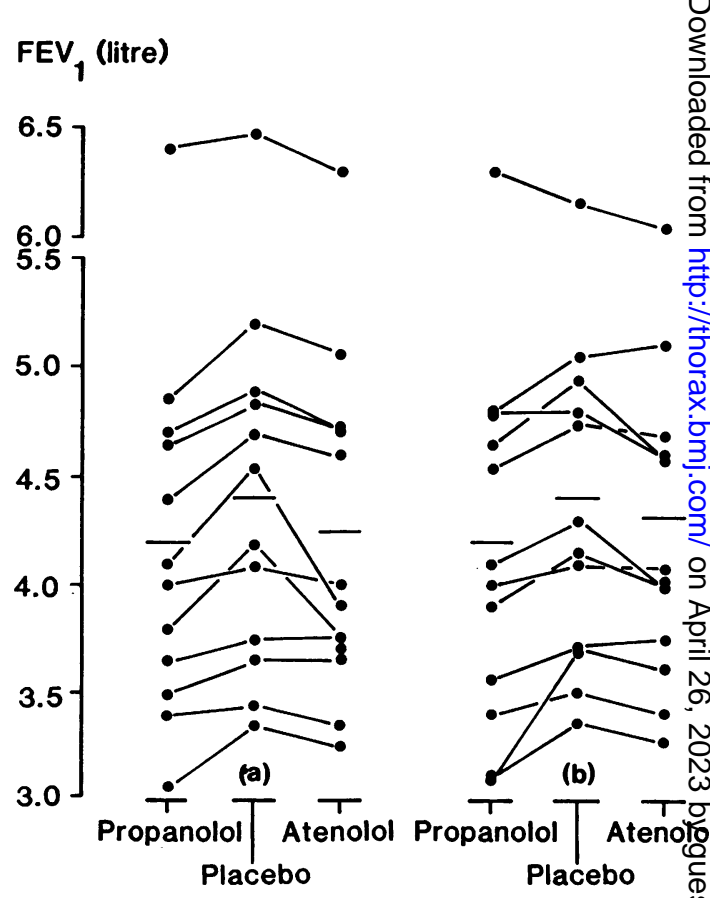

Fig 1 Individual and mean (-) values of $F E V_{1}$ for 12 healthy subjects (a) two hours and (b) eight hours after administration of placebo, propranolol (160 mg), and atenolol $(100 \mathrm{mg})$. At both times the results after proprano: and the results after atenolol are significantly different from those after placebo $(p<0.01)$. 


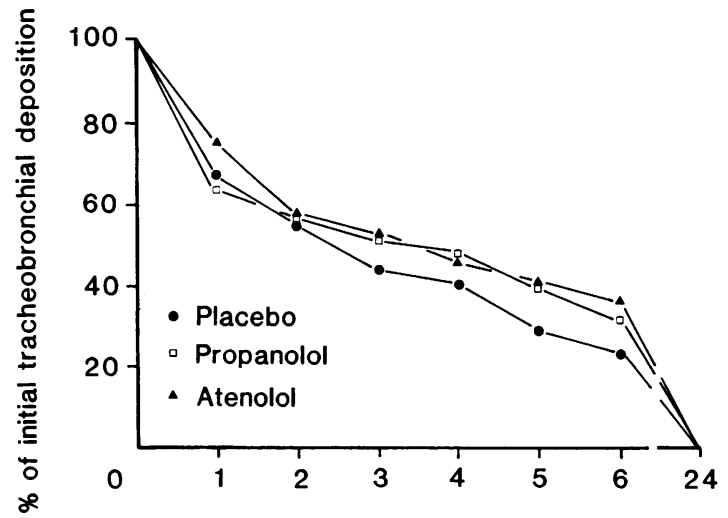

Time after inhalation of radioaerosol (h)

small but nevertheless significant falls in FVC ${ }^{\circ}$ were noted for the same time intervals. By 24 hours after treatment the differences in $\mathrm{FEV}_{1}$ and FVC between the effects of the beta blockers and those of the placebo were no longer significant. None of the other pulmonary function indices (that is, PEF, $\mathrm{FEF}_{25-75}$, $\dot{V} \max _{50}$ and $\dot{V} \max _{25}$ ) showed any differences between medication with either drug and with placebo.

There was a significant fall in pulse rate after both beta blockers by comparison with placebo, which lasted for eight hours after administration. Systolic blood pressure also fell with both drugs (for propranolol $\mathrm{p}<0.05$; for atenolol $\mathrm{p}<0.01$ ), but diastolic pressure was reduced only with atenolol during the first three hours.

Fig 2 Mean tracheobronchial clearance curves for 12 healthy subjects after placebo, propranolol (160 mg) and atenolol (100 $\mathrm{mg}$ ) given two hours before the inhalation of the radioaerosol.

radioaerosol unavailable for clearance via the mucociliary escalator. ${ }^{16}$

A gamma scanner ${ }^{17}$ was used to obtain a quantitative index of initial deposition, the penetration index (PI); this was derived as the ratio of the amount of ${ }^{99 \mathrm{~m}} \mathrm{Tc}$ activity present in an outer region of the right lung relative to that in an inner region. This index attempts to measure the extent to which the radioaerosol particles are distributed towards the periphery of the lungs.

The smokers did not smoke for one hour before or during the six hour tracheobronchial mucociliary clearance observation period.

\section{STATISTICAL ANALYSIS}

The Friedman two-way analysis of variance by ranks and the Wilcoxon test for pair differences were used to analyse the data.

\section{Results}

PULMONARY FUNCTION, PULSE RATE, AND BLOOD PRESSURE

Figure 1 shows the individual $\mathrm{FEV}_{1}$ values for the study group ( $a$ ) two hours and $(b)$ eight hours after the administration of propranolol, placebo and atenolol. At both times observations after propranolol, atenolol, and placebo were significantly different (at two hours $\chi_{\mathrm{r}}^{2}=16.73$ ( $\mathrm{p}<0.005$ ); at eight hours $\left.\chi_{\mathrm{r}}^{2}=9.48(\mathrm{p}<0.01)\right)$. At both times $\mathrm{FEV}_{1}$ was significantly $(\mathrm{p}<0.01)$ lower with both beta blocking drugs than with placebo (mean (SEM) $\mathrm{FEV}_{1}$ after placebo, propranolol, and atenolol: 4.4 (0.3), $4.2(0.4)$, and $4.25(0.3) ; 4.4(0.2), 4.2(0.3)$, and $4.3(0.2) 1$ at two and eight hours respectively). Similar

\section{TRACHEOBRONCHIAL MUCOCILIARY CLEARANCE}

The means (SE) of the average inspiratory flow rates after placebo, propranolol, and atenolol were 25 (1), 30 (3), and 28 (3) $1 \min ^{-1}\left(\chi_{\mathrm{r}}^{2}=3.79, \mathrm{p}<0.10\right)$. The mean (SE) penetration indices were similar: $0.64(0.05)$ with placebo, $0.66(0.05)$ with propranolol, and $0.66(0.06)$ with atenolol. The similarity in penetration indices was supported by the similar mean (SE) alveolar depositions attained in the three runs: $62 \%(4 \%)$ with placebo, $58 \%(5 \%)$ with propranolol, and $57 \%(3 \%)$ with atenolol.

Figure 2 shows the mean tracheobronchial mucociliary clearance curves obtained with placebo, propranolol, and atenolol. The mean clearance curves appear similar over the first two hours, thereafter diverging with both beta blocker drugs and showing a slower clearance than was found with placebo. The curves were analysed by comparing $(a)$ the areas under the individual curves for two time intervals: $0-3$ hours and 3-6 hours after inhalation of radioaerosol (the smaller the area the faster the mucociliary clearance) and $(b)$ the percentages of radioaerosol retained at hourly intervals. The areas under the curves were calculated by the trapezoidal rule. There was no significant difference between the areas under the three curves for 0-3 hours. For 3-6 hours, however, there was a significant difference $\left(\chi_{\mathrm{r}}^{2}=6.17, \mathrm{p}<\right.$ 0.05 ), indicating slowing (that is, increase in the areas under the curves) of lung clearance with both beta blockers. The Wilcoxon test for paired differences in the areas under the curves for 3-6 hours between the placebo and drug runs indicated a significant ( $p<$ 0.02 ) slowing of mucociliary clearance after propranolol only by comparison with placebo. This difference was also evident from the radioaerosol retained at three hours $(p<0.05)$, four hours $(p<$ $0.02)$, and five hours $(p<0.05)$. The difference 
between atenolol and placebo approached significance $(p<0.10)$ at four and five hours only.

\section{Discussion}

A similar degree of beta blockade was achieved after the administration of $160 \mathrm{mg}$ of propranolol and $100 \mathrm{mg}$ of atenolol. Both drugs resulted in significant falls in $\mathrm{FEV}_{1}$ and $\mathrm{FVC}$ of $5 \%$, lasting for eight hours, returning to normal by 24 hours. These reductions were, however, so small as to be of no clinical consequence for this healthy group. The other pulmonary function indices (including those predominantly reflecting function of the small airways), were, surprisingly, unaltered.

Results of measurement of tracheobronchial mucociliary clearance are influenced to an important extent by the initial site of radioaerosol deposition. Proximal deposition gives rise to apparently faster clearance than does distal deposition in the lungs. ${ }^{18}$ Factors that affect the initial topographical distribution of aerosol in the lung are: $(a)$ the physical properties of the radioaerosol $(b)$ the mode of inhalation, and $(c)$ airway patency. ${ }^{1920}$ In this study $(a)$ and $(b)$ were similar for all three runs; $(c)$, however, was slightly different between runs since $\mathrm{FEV}_{1}$ and FVC were reduced after propranolol and atenolol. Nevertheless, the two indices of initial topographical distribution-alveolar deposition and penetration index - were virtually identical in the three runs, so that the tracheobronchial mucociliary clearance curves could be compared directly.

The Friedman two way analysis of variance by ranks indicated a significant $(\mathrm{p}<0.05)$ slowing of tracheobronchial mucociliary clearance after beta blockade during the period three to six hours after radioaerosol inhalation - that is, from five to eight hours after the administration of the drug. Although on average the degree of slowing was similar with the two drugs, when they were compared with placebo statistical significance $(p<0.02)$ was attained only with propranolol. In general, the initial part ( 0 to about 3 hours) of the clearance curve represents mucociliary clearance of deposited radioaerosol from the proximal ciliated airways, whereas the later part (that is, about 3-6 hours) is taken to represent removal of radioaerosol from the more distal ciliated airways. ${ }^{21}$ This study indicated a $32 \%$ increase on average in the areas under the curves for 3-6 hours (that is, slowing of mucociliary clearance distally) in healthy subjects after a single dose of a selective ( $p<$ $0.10)$ or a non-selective $(p<0.02)$ beta blocker.

Efficient tracheobronchial mucociliary clearance depends on the integrity of the ciliated epithelium, ciliary beat frequency, and coordination, the thickness and consistency of the periciliary layer, and the physicochemical properties and quantity of the ep⿳亠丷厂 phase. With in vitro experiments in animals low co centrations of propranolol $(0.1 \mu \mathrm{mol} / \mathrm{l})$ have bee shown to block the cilioexcitatory effect of beta age nists. On the other hand, similar concentrations propranolol (in the absence of beta agonists) have been reported to show no effect on ciliary activity. High concentrations of propranolol $(100 \mu \mathrm{mol} / \mathrm{l})$ decrease ciliary beat frequency, possibly owing to the local anaesthetic properties of the drug. The role of sympathomimetic agents on airway mucus secretions in man appears to be a matter of debate. ${ }^{23-25}$ Both and $\beta$ adrenergic agents have been shown, in anim studies, to increase mucus glycoprotein and/or io and water transport into the lumen of the airways. 26 Chopra and colleagues ${ }^{27}$ reported that the intriy venous administration of 3-5 mg propranolol hydro chloride to lightly anaesthetised dogs did not alte tracheal mucus velocities measured 15 minutes after: wards. In the only studies carried out in man Matth et $a l^{28}$ administered $20 \mathrm{mg}$ of pindolol daily for thre days to seven patients with chronic bronchitis and reported a retardation in mucociliary clearance rats Dorow et $\mathrm{al}^{29}$ gave propranolol $40 \mathrm{mg}$ twice daily $\dot{\theta}$ six subjects with coronary heart disease (and norm\$1 lung function) and observed significantly slowe mucociliary clearance than with placebo.

Impairment of mucociliary clearance has beç shown to precede atelectasis ${ }^{30}$ and has been impli cated in the development of chronic airway obstruo tion. ${ }^{31}$ Our observations have shown that single doses of selective and non-selective beta blockers can cause reduced pulmonary function and mucociliary transt port in healthy subjects. This raises the question of what effect they may have in long term administration to patients who have cardiovascular disease withoưt accompanying airways dysfunction.

We thank the volunteer subjects who participated the study; Nóirin F Sheahan, who helped with cof lating the data; and Imperial Chemical Industries Lte (Pharmaceuticals Division) for providing the druss and financial support.

\section{References}

I Pavia D, Bateman JRM, Clarke SW. Deposition ang clearance of inhaled particles. Bull Europ Physiopath Respir 1980;16:335-66.

2 Camner P, Strandberg K, Philipson K. Increas mucociliary transport by adrenergic stimulation. Arch Environ Health 1976;39:79-82.

3 Konietzko N, Klopfer M, Adam WE, Matthys H, D花 mukociliare Klarfunktion der Lunge unter beta adie nerger Stimulation. Pneumologie 1975;152:203-8.

4 Santa Cruz R, Landa J, Hirsch J, Sackner MA. Trache@ mucous velocity in normal man and patients wị 
obstructive lung disease: effects of terbutaline. Am Rev Respir Dis 1974;109:458-63.

5 Sill V, Novak D, Kaukel E, Lanser K. Schatzung der mukoziliaren Clearance mittels Pharmakobronchographie. Prax Pneumol 1976;30:339-43.

6 Spektor DM, Pitt BR, Yeates DB. Changes in regional mucociliary transport in the human lung resulting from systemic beta ${ }_{2}$-adrenergic stimulation. Am Rev Respir Dis 1979;119, suppl:236.

7 Foster WM, Bergofsky EH, Bohning DE, Lippmann M, Albert RE. Effect of adrenergic agents and their mode of action on mucociliary clearance in man. J Appl Physiol 1976;41:146-52.

8 Yeates DB, Aspin N, Levison H, Jones MT, Bryan AC. Mucociliary tracheal transport rates in man. $J$ Appl Physiol 1975;39:487-95.

9 Fazio F, Lafortuna C. Effect of inhaled salbutamol on mucociliary clearance in patients with chronic bronchitis. Chest $1981 ; 80$, suppl:827-30.

10 Burge PS. Trigger Factors in asthma. In: Clark TJH, ed. Steroids in asthma: a reappraisal in the light of inhalation therapy. Auckland: Adis Press, 1983:61-82.

11 Cotes JE. Lung function: assessment and application in medicine. 4th ed. Oxford: Blackwell Scientific Publications, 1979.

12 Knudson RJ, Lebowitz MD, Holberg CJ, Burrows B. Changes in the normal maximal expiratory flow-volume curve with growth and aging. Am Rev Respir Dis 1983;127:725-34.

13 Pavia D, Sutton PP, Agnew JE, Lopez-Vidriero MT, Newman SP, Clarke SW. Measurement of bronchial mucociliary clearance. Eur J Respir Dis 1983;64, suppl 127:41-56.

14 Few JD, Short MD, Thomson ML. Preparation of ${ }^{99} \mathrm{Tc}^{\mathrm{m}}$ labelled particles for aerosol studies. Radiochem Radioanal Lett 1970;5:275-7.

15 Thomson ML, Pavia D. Long-term tobacco smoking and mucociliary clearance from the human lung in health and respiratory impairment. Arch Environ Health 1973;26:86-9.

16 Camner P, Philipson K. Human alveolar deposition of 4 $\mu \mathrm{m}$ Teflon particles. Arch Environ Health 1978;35:181-5.

17 Dawson H, Douglas RB, Pavia D, Reeves E, Short MD, Thomson ML. An inexpensive automatic two detector lung scanner. Phys Med Biol 1971;16:691-2.

18 Thomson ML, Short MD. Mucociliary function in health, chronic obstructive airways disease, and asbestosis. J Appl Physiol 1969;26:535-9.

19 Foord N, Black A, Walsh M. Pulmonary deposition of inhaled particles with diameters in the range 2.5 to 7.5 $\mu \mathrm{m}$. In: Walton WH, ed. Inhaled particles IV. Oxford: Pergamon Press, 1977:137-48.

20 Pavia D, Thomson ML, Clarke SW, Shannon HS. Effect of lung function and mode of inhalation on penetration of aerosol into the human lung. Thorax 1977;32:194-7.

21 Sutton PP, Pavia D, Bateman JRM, Clarke SW. The effect of oral aminophylline on lung clearance in man. Chest $1981 ; 80$, suppl:889-91.

22 Verdugo P, Johnson NT, Tam P. Beta-adrenergic stimulation of respiratory ciliary activity. $J$ Appl Physiol: Respir Environ Exercise Physiol 1980;48:868-71.

23 Sturgess J, Reid L. An organ culture study of the effect of drugs on the secretory activity of the bronchial submucosal gland. Clin Sci 1972;43:533-43.

24 Boat TF, Kleinerman JI. Human respiratory tract secretions: 2 . Effect of cholinergic and adrenergic agents on in vitro release of protein and mucous glycoprotein. Chest 1975;67, suppl:32-4.

25 Phipps RJ. Adrenergic stimulation of mucus secretion in the human bronchus. [abstract]. J Physiol 1979;296:44P.

26 Lopez-Vidriero MT. Airway mucus-production and composition. Chest 1981;80, suppl:799-804.

27 Chopra SK, Carson SA, Tashkin DP, Taplin GV, Elam D. Effect of terbutaline and inderol on tracheal transport velocity in anesthetized dogs. Am Rev Respir Dis 1979;119, (No 4 part 2):206.

28 Matthys H, Vastag E, Daikeler G, Kohler D. The influence of aminophylline and pindolol on the mucociliary clearance in patients with chronic bronchitis. Br J Clin Pract 1983;supp. 23:82-6.

29 Dorow P, Weiss T, Felix R, Schmutzler H, Schiess W. Influence of propranolol, metoprolol, and pindolol on mucociliary clearance in patients with coronary heart disease. Respiration 1984;45:286-90.

30 Gamsu G, Singer MM, Vincent HH, Berry S, Nadel JA. Post-operative impairment of mucous transport in the lung. Am Rev Respir Dis 1976;114:673-9.

31 Mossberg B, Afzelius BA, Eliasson R, Camner P. On the pathogenesis of obstructive lung disease. A study on the immotilecilia syndrome. Scand J Respir Dis 1978; 59:55-65. 